JURNAL SISFOTENIKA

Vol. 10 No. 1, Januari 2020

p-ISSN: 2087-7897; e-ISSN : 2460-5344

DOI : $10.30700 /$ jst.v10i1.949

\title{
Pemilihan Paket Wedding Menggunakan Metode Electre
}

\section{Selection of Wedding Packages Using the Electre Method}

\author{
Endah Sri Subrata, Susanti Margaretha Kuway, I Dewa Ayu Eka Yuliani \\ STMIK Pontianak;Jl. Merdeka Barat no. 372, (0561) 735555 \\ Jurusan Teknik Informatika, STMIK Pontianak, Pontianak \\ e-mail: een363@gmail.com, kuwayshanty@gmail.com, dewaayu.ekayuliani@gmail.com
}

\begin{abstract}
Abstrak
Seiring dengan perkembangan teknologi yang semakin pesat dan tidak bisa dipungkiri bahwa teknologi sebagai kebutuhan sekunder bagi para penggunanya. Sejauh ini teknologi juga telah diterapkan pada beberapa bidang, salah satu contohnya kehadiran teknologi di sektor pendidikan yang memudahkan para penggunanya untuk melakukan proses pemilihan paket wedding. Sistem pendukung keputusan ini untuk menentukan kriteria-kriteria dalam mengatasi masalah yang dihadapi suatu pernikahan dalam memberikan informasi yang tepat waktu, akurat dan efisien untuk mereka yang membutuhkan informasi tersebut, dimana informasi yang terkandung dalam media penyimpanan data yang khusus disiapkan. Penelitian menggunakan metode ELECTRE untuk proses perhitungannya dan aplikasi berbasis web dengan bahasa pemograman PHP yang bisa di akses setiap pengguna dimanapun pengguna berada berdasarkan kriteria hasil tersebut pengguna dapat menentukan kriteria mana yang akan diambil dan sesuai dengan budget.
\end{abstract}

Kata kunci-ELECTRE, Wedding, Sistem pendukung Keputusan, Extreme Programming

\begin{abstract}
Abstrak
Along with the development of technology that is increasingly rapidly and it cannot be denied that the technology as secondary to the needs of its users. So far this technology has also been applied to several fields, one example the presence of technology in the education sector which allows its users to do the wedding package selection process. This decision support system for determining criteria in addressing the issues facing a marriage in providing information that is timely, accurate and efficient for those who need the information, where the information contained in the data storage medium that is specially prepared. Research using ELECTRE method for calculation process and web-based applications with PHP programming language that can access each user regardless of where the user is based on the criteria of the results users can determine which criteria will be taken and according to the budget.
\end{abstract}

Kata kunci-ELECTRE, Wedding,, decision support system, Extreme Programming 


\section{PENDAHULUAN}

Pernikahan merupakan bentuk hubungan antar manusia yang paling sacral dan utama. Sehingga setiap pasangan akan melakukan persiapan yang total untuk menghadapi pernikahan. Persiapan itu antara lain kelengkapan terselenggaranya sebuah pernikahan. Karena sekali seumur hidup, tentunya kemasan sebuah pernikahan akan dibuat harus sebaik mungkin. Hal-hal seperti ini yang sering kali menyulitkan dan membingungkan para calon pengantin ketika minimnya informasi yang dapat dijadikan acuan dalam pengambilan keputusan tentang pemilihan paket wedding.

Penelitian yang dilakukan oleh Anhar dalam penelitian ini Perancangan Aplikasi Pengambilan Keputusan Penentuan Paket Tujuan Wisata Menggunakan Metode TOPSIS (Studi Kasus PT. Vina Tour dan Travel Medan), penelitian ini termasuk dalam Multi Atribut Decision Making (MADM). Metode yang digunakan metode TOPSIS (Technique for Order Preference by Similiarty to Ideal Solution). Tujuan dari penelitian ini yaitu untuk membantu konsumen menentukan paket wedding dengan cara merancang sebuah aplikasi pendukung keputusan penentuan paket wisata berdasarkan kriteria yang diinputkan oleh konsumen untuk mendapatkan informasi paket wisata yang sesuai dengan keinginan dan kebutuhan konsumen.[1]

Menurut Setiawan, Indriani, Muliadi melakukan penelitian tentang "Implementasi Metode ELECTRE Pada Sistem Pendukung Keputusan SNMPTN Jalur Undangan". Pada penelitian ini dibangun Sistem Pendukung Keputusan berbasis web dengan menggunakan metode analisis pengambilan keputusan multikriteria yaitu ELECTRE. Menggunakan metode ELECTRE karena permasalahan ini sesuai dan cocok pada konsep perangkingan berdasarkan alternatif dan kriteria yang telah ditetapkan. Metode ELECTRE ini dapat digunakan pada kondisi dimana alternatif yang kurang sesuai dengan kriteria dieliminasi dan alternatif yang sesuai dapat dihasilkan. Keluaran dari sistem ini berupa laporan hasil perankingan calon mahasiswa yang lebih layak masuk di Universitas Lambung Mangkurat sesuai program studi yang diminatinya.[2]

Menurut Setiwati, Hartati, Maulana melakukan penelitian tentang "Sistem Pendukung Keputusan Pembelian Barang Menggunakan Metode ELECTRE". Dalam melakukan pembelian barang, ada beberapa kriteria yang digunakan oleh Denco Variasi. Kriteria tersebut antara lain, jumlah penjualan barang pada periode sebelumnya dan laba yang didapat dari penjualan tersebut, ketersediaan stok barang di gudang, besarnya modal yang dialokasikan untuk melakukan pembelian. Setelah melakukan analisa, merancang sistem dan membuat aplikasi sistem pendukung keputusan pembelian barang menggunakan metode ELECTRE, serta keputusan ini telah berjalan dengan baik dan sesuai dengan yang diharapkan. Data alternatif yang digunakan didapat dari data penjualan berdasarkan periode yang dipilih, data barang dengan stok minimum dan kategori yang ditentukan. Berikut merupakan proses pembobotan alternatif untuk tiap kriteria yang digunakan.[3]

Penelitian ini menggunakan metode ELECTRE sebagai metode dalam pendukung keputusan ini karena ELECTRE dapat digunakan dalam menyelesaikan berbagai jenis kasus pengambilan keputusan melalui perhitungan yang dapat memberikan nilai preferensi untuk alternatif, dan mampu memilih alternatif terbaik dari alternatif lain, alternative yang dimaksud dalam penelitian ini adalah paket wedding di Pontianak. 


\section{METODE PENELITIAN}

Penelitian ini menggunakan bentuk penelitian berupa berupa studi kasus yaitu bentuk penelitian yang memusatkan perhatian pada suatu kasus tertentu dengan menggunakan individu atau kelompok sebagai bahan studinya. Metode yang digunakan dalam penelitian ini adalah metode penelitian Research and Development (R\&D).

Teknik perancangan perangkat lunak menggunakan UML (Unified Modeling Language) adalah salah satu alat bantu yang sangat handal di dunia pengembangan sistem yang berorientasi objek. Use case diagram merupakan salah satu diagram untuk memodelkan aspek perilaku sistem. Diagram use case adalah penting untuk menvisualisasikan, menspesifikasikan, dan mendokumentasikan kebutuhan perilaku sistem . Sequence diagram digunakan untuk menggambarkan perilaku pada sebuah skenario. Diagram ini menunjukan sejumlah contoh obyek dan message (pesan) yang diletakan antara objek-objek ini didalam use case. Activity diagram adalah teknik untuk mendeskripsikan logika prosedural, proses bisnis dan aliran kerja dalam banyak kasus. Diagram kelas merupakan diagram paling umum dipakai di semua pemodelan berorientasi objek.

Metode black box, berfokus pada persyaratan fungsional perangkat lunak. Artinya, teknik pengujian black box memungkinkan untuk membuat beberapa kumpulan kondisi masukan yang sepenuhnya akan melakukan semua kebutuhan fungsional untuk program. Simpul merepresentasikan suatu objek (seperti modul atau koleksi statemen), link merepresentasikan hubungan antar objek, node weight menggambarkan properti simpul (atribut). link weight menggambarkan beberapa karakteristik link.

\section{HASIL DAN PEMBAHASAN}

Penelitian yang peneliti lakukan dalam mengembangkan aplikasi system pendukung keputusan ini menggunakan metode Extreme Programming memiliki tahapan pengembangan yang dinamis, serta memiliki tahapan pengembangan diantaranya tahap planning, design, coding, dan tester. Dengan menggunakan metode Extreme Programming ini penulis dapat memangakas kriteria yang sesuai dengan kebutuhan konsumen. kepuasan pengguna dalam memilih paket sesuai kebutuhan dan budget atas aplikasi yang dihasilkan.

Tahap planning merupakan tahap dimana peneliti mengidentifikasi setiap kebutuhan yang di perlukan dalam pengembangan aplikasi. Pada tahap ini juga peneliti juga mengumpulkan data-data yang dibutuhkan untuk pengujian aplikasi. Penelitian melakukan beberapa cara dalam mengumpulkan data diantaranya dengan melakukan wawancara di FAMOUS Bridal untuk mendapatkan informasi secara lisan dengan tujuan untuk memperoleh data yang dapat menjelaskan ataupun menjawab suatu permasalahan dalam penelitian kemudian melakukan dokumentasi terhadap apa yang diperlukan oleh aplikasi dengan mencari data berupa, tulisan dan dokumentasi lainnya yang mengenai hal-hal yang berkaitan dengan aplikasi atau variabel yang diperlukan. Selanjutnya melakukan observasi, yaitu mengamati langsung sistem yang sedang berjalan pada bridal-bridal di Pontianak agar bisa dipelajari dan diterapkan terhadap aplikasi yang peneliti rancang. Sementara itu aplikasi yang dihasilkan dengan menggunakan PHP dan memanfaatkan data MySQL sebagai tempat penyimpanan data

Analisis kebutuhan sistem merupakan proses menganalisis serta pemodelan untuk mencari kebutuhan dari seluruh sistem yang sesuai dengan antar muka yang akan dibangun. Aplikasi Sistem Pendukung Keputusan ini menggunakan metode pengembangan Waterfall model yang merupakan metodologi untuk pengembangan sistem secara cepat serta memodelkan sistem kedalam UML (Unified Modelling Language). Yang terdiri dari Class Diagram yang menggambarkan struktur sistem yang mendefinisikan kelas-kelas yang akan dibuat untuk membangun sistem, kemudian Use Case Diagram yang mendeskripsikan sebuah interaksi antara satu atau lebih actor dengan sistem informasi, selanjutnya adalah Activity Diagram yang 
menggambarkan alur kerja dari sebuah sistem yang ada, serta terakhir adalah Squence Diagram yang menggambarkan tujuan dari setiap komponen sistem. Sistem yang digunakan dalam implementasi aplikasi ini terbagi menjadi dua perangkat. Perangkat tersebut yaitu perangkat lunak dan perangkat keras.

Perangkat Keras

Berikut adalah spesifikasi perangkat keras yang dibutuhkan oleh sistem untuk melakukan pembuatan aplikasi Sistem Pendukung Keputusan:

a. Processor intel core i3

b. Memori 2 GB

c. Monitor

d. Keyboard

Berikut adalah spesifikasi perangkat lunak yang dibutuhkan oleh sistem untuk melakukan pembuatan aplikasi Sistem Pendukung Keputusan:

a. PHP

b. Xampp

c. Crystal Report

d. Sistem operasi Windows 7

Interface Design perancangan perangkat lunak Sistem Pendukung Keputusan , mendefinisikan interface-interface diantara komponen sistem dan spesifikasi interface tidak boleh ambigu. Merancang antarmuka merupakan bagian yang paling penting dari merancang sistem. Biasanya hal tersebut juga merupakan bagian yang paling sulit karena dalam merancang antarmuka harus memenuhi tiga persyaratan: sebuah antarmuka harus sederhana (user friendly), sebuah antarmuka harus lengkap (complete interface), dan sebuah antarmuka harus memilki kinerja yang cepat (fast performace). Alasan utama mengapa antarmuka sulit untuk dirancang adalah karena setiap antarmuka adalah sebuah bahasa pemrograman yang kecil antarmuka menjelaskan sekumpulan objek-objek dan operasi-operasi yang bisa digunakan untuk memanipulasi objek.

Pada gambar 1 Merupakan perancangan interface pada login, dari terdapat dua textbox untuk mengisi username dan password admin. Dan satu button login, untuk memproses hasil inputan dari username dan password.

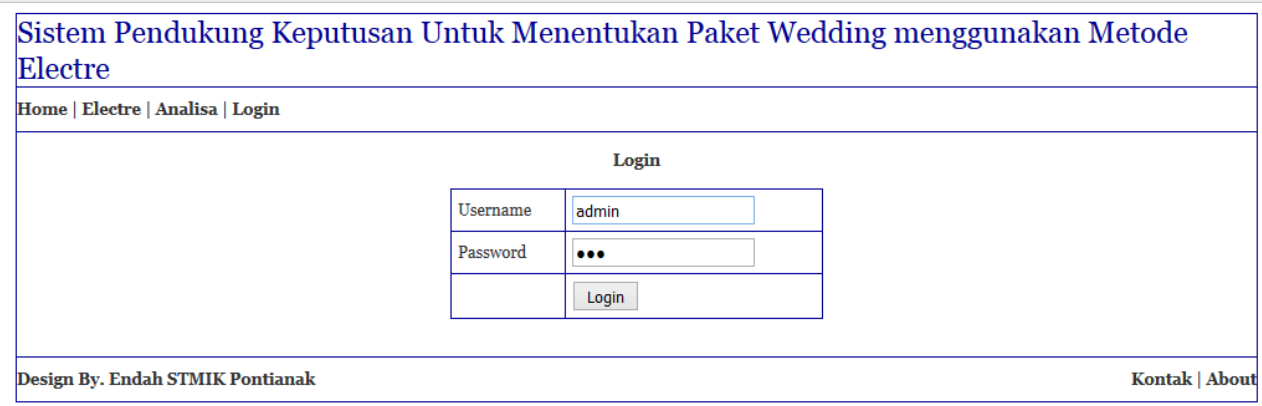

Gambar.1 Desain form login

Pada gambar 1 merupakan desain form login, terdapat dua textbox untuk mengisi username dan password admin. Ketika username dan password sudah diisi klik login untuk memproses hasil inputan kemudian akan masuk ke form utama.

Perancangan struktur menu ini digunakan untuk mempermudah pengguna dalam mengoperasikan aplikasi yang dibangun atau ataupun dikembangkan. Dengan adanya struktur 
menu sistem tentunya akan membantu pengguna dalam menjalankan aplikasi sesuai dengan menunya. Adapun rancangan struktur menu sistem yang peneliti rancang adanya sebagai berikut:

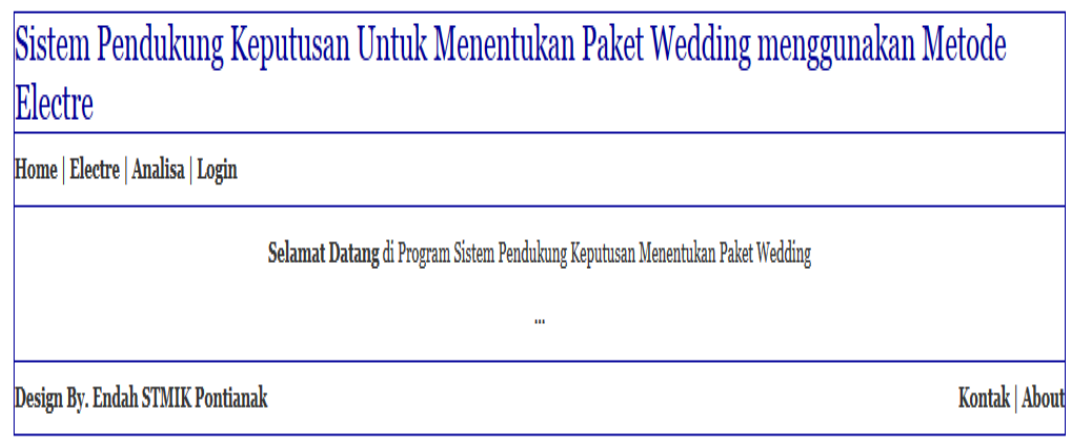

Gambar 2 Desain form utama

Form utama adalah form yang muncul setelah memilih form login berhasil form utama terdiri dari beberapa menu, diantaranya Home, Electre, Analisis, Login.

\begin{tabular}{|c|c|c|c|}
\hline \multicolumn{4}{|l|}{ SPK Metode Electre } \\
\hline \multicolumn{4}{|c|}{ Home | Alternatif | Kriteria | Alternatif Kriteria | Ganti Password | Logout | Anda Login Sebagai : admin } \\
\hline \multicolumn{4}{|c|}{ Data Alternatif } \\
\hline ID Alternatif & Nama Alternatif Produk & Deskripsi & Add \\
\hline 1 & Paket Weding 1 & - Biaya Rp. 100.000 .000 & Edit Del \\
\hline 2 & Paket Weding 2 & -Biaya Rp. 150.000 .000 & Edit Del \\
\hline 3 & Paket Weding 3 & -Biaya > Rp. 150.000.000 & Edit Del \\
\hline
\end{tabular}

Gambar 3. Desain Form Alternatif/Produk

Merupakan form yang didesain untuk menginputkan daftar paket wedding terdapat menu tambah, ubah dan hapus data seperti penginputan nama Alternatif Produk, ID Alternatif, Deskripsi.

\begin{tabular}{|c|c|c|c|c|}
\hline \multicolumn{5}{|c|}{ SPK Metode Electre } \\
\hline \multicolumn{5}{|c|}{ Home | Alternatif | Kriteria | Alternatif Kriteria | Ganti Password | Logout | Anda Login Sebagai : admin } \\
\hline \multicolumn{5}{|c|}{ Data Kriteria } \\
\hline & ID Kriteria & Nama Kriteria & Bobot & Add \\
\hline & 1 & Wedding Organizer & 5 & Edit Del \\
\hline & 2 & Decoration & 3 & Edit Del \\
\hline & 3 & Wedding Photography & 4 & Edit Del \\
\hline & 4 & Wedding Videography & 4 & Edit Del \\
\hline & 5 & Catering & 2 & EditDel \\
\hline & 6 & Wedding Card & 8 & EditDel \\
\hline & 7 & Photobooth & 7 & Edit Del \\
\hline
\end{tabular}

Gambar 4 Desain form kriteria paket wedding

Desain form kriteria yang terdapat dalam paket wedding yang didesain untuk melakukan proses penginputan kriteria terdapat menu tambah data seperti nama kriteria, id 
Pemilihan Paket Wedding Menggunakan Metode Electre ...

kriteria, nilai bobot. Kemudian dari data yang sudah diinputkan bisa diubah dan dihapus setelah penginputan selesai. terdapat dua menu button yaitu simpan data dan batal.

\begin{tabular}{|c|c|c|c|c|}
\hline \multicolumn{5}{|c|}{ Home | Alternatifi | Kriteria | Alternatif Kriteria | Ganti Password | Logout | Anda Login Sebagai : admin } \\
\hline \multicolumn{5}{|c|}{ Data Kriteria } \\
\hline ID Altenatif Kiteria & Nama Alternatif & Nama Kiteria & Niai & Add \\
\hline 16 & Paket Weding1 & Wedding Organizer & 7 & Editit Del \\
\hline 17 & Paket Weding 1 & Deoration & 8 & Editit Del \\
\hline 3 & Paket Weding 1 & Wedding Phatography & 5 & EdititDel \\
\hline 2 & Paket Weding 1 & Wedding Tideovgraphy & 8 & 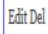 \\
\hline 5 & Paket Weding 1 & Catering & 3 & EdititDel \\
\hline 6 & Paket Weding 2 & Wedding Oryaniver & 3 & EdititDel \\
\hline 7 & Paket Weding 2 & Deeoration & 3 & EdititDel \\
\hline 8 & Paket Weating 2 & Wedding Photography & 4 & EdititDel \\
\hline 9 & Paket Weding 2 & Wedding Tideograply & 2 & EalitDel \\
\hline 10 & Peket Weding 2 & Catering & 3 & E⿺辶itDd \\
\hline 11 & Paket Weding 3 & Wedding Organiver & 5 & EdititDel \\
\hline 12 & Pakket Wedings & Decoration & 4 & EalitDel \\
\hline 13 & Paket Wedings & Wedding Photography & 2 & Editit Del \\
\hline 4 & Paket Weding 3 & Wedding Videography & 2 & Editit Del \\
\hline 15 & Paket Weding 3 & Catering & 2 & EdititDel \\
\hline
\end{tabular}

Gambar 5 Desain form Alternatif kriteria

Pada desain from Alternatif kriteria merupakan form yang didesain untuk melakukan proses penginputan pilihan paket wedding beserta kriteria . kemudian dari data yang sudah diinputkan bisa diubah dan dihapus setelah penginputan selesai terdapat dua menu button yaitu simpan data dan batal.

Langkah-langkah seleksi (perhitungan) pada metode ELECTRE adalah sebagai berikut:

1. Normalisasi matrik keputusan

$$
\begin{aligned}
& r 25=\frac{x 25}{\sqrt{\sum_{i}^{m}=1 x_{i 5}^{2}}}=\frac{3}{\sqrt{3^{2}+3^{2}+2^{2}}}=\frac{3}{4,690}=0,396 \\
& r 31=\frac{x 31}{\sqrt{\sum_{i}^{m}=1 x_{i 1}^{5}}}=\frac{5}{\sqrt{4^{2}+3^{2}+5^{2}}}=\frac{5}{7,071}=0,7071 \\
& r 32=\frac{x 32}{\sqrt{\sum_{i}^{m}=1 x_{i 2}^{2}}}=\frac{4}{\sqrt{4^{2}+3^{2}+4^{2}}}=\frac{4}{6,403}=0,6247 \\
& r 33=\frac{x 33}{\sqrt{\sum_{i}^{m}=1 x_{i 3}^{2}}}=\frac{2}{\sqrt{5^{2}+4^{2}+2^{2}}}=\frac{2}{6,7082}=0,2981 \\
& r 34=\frac{x 34}{\sqrt{\sum_{i}^{m}=1 x_{i 4}^{2}}}=\frac{2}{\sqrt{3^{2}+3^{2}+2^{2}}}=\frac{2}{4,690}=0,4264
\end{aligned}
$$

Dari perhitungan di atas diperoleh hasil : 
2. Pembobotan pada matrik yang ternormalisasi

$\begin{array}{lllll}0,5657 & 0,6247 & 0,7454 & 0,7276 & 0,6396 \\ 0,4243 & 0,4685 & 0,5963 & 0,4851 & 0,6396 \\ 0,7071 & 0,6247 & 0,2981 & 0,4851 & 0,4264\end{array}$

$$
\begin{aligned}
& \begin{array}{lllll}
0,5657 & 0,6247 & 0,7454 & 0,7276 & 0,6396
\end{array} \\
& \begin{array}{llllll}
0,4243 & 0,4685 & 0,5963 & 0,4851 & 0,6396
\end{array} \\
& \begin{array}{lllll}
0,7071 & 0,6247 & 0,2981 & 0,4851 & 0,4264
\end{array} \\
& \begin{array}{lllll}
5 & 0 & 0 & 0 & 0
\end{array} \\
& \begin{array}{lllll}
0 & 3 & 0 & 0 & 0
\end{array} \\
& \begin{array}{lllll}
0 & 0 & 4 & 0 & 0
\end{array} \\
& \begin{array}{lllll}
0 & 0 & 0 & 4 & 0
\end{array} \\
& \begin{array}{lllll}
0 & 0 & 0 & 0 & 2
\end{array} \\
& \begin{array}{lllll}
2,8285 & 1,8741 & 2,9816 & 2,9104 & 1,2792
\end{array} \\
& \begin{array}{lllll}
2,1215 & 1,4055 & 2,3853 & 1,9404 & 1.2792
\end{array} \\
& 3,5355 \quad 1,8751 \quad 1,1924 \quad 1,9404 \quad 0,8528
\end{aligned}
$$

3. Menentukan himpunan concordance dan discordance indek

a. Concordance

Sebuah Kriteria dalam alternatif termasuk concordance

$$
C_{k l}=\left\{j, V_{k j} \geq V_{k j}\right\}, \text { Untuk j }=1,2,3, \ldots, \mathrm{n}
$$

$C_{12}=\left\{j, V_{1 j} \geq V_{2 j}\right\}$, Untuk $\mathrm{j}=1,2,3, \ldots, 5$

$$
=\{1,2,3,4,5\}
$$

$C_{13}=\left\{j, V_{1 j} \geq V_{3 j}\right\}$, Untuk $\mathrm{j}=1,2,3, \ldots, 5$ $=\{2,3,4,5\}$

$C_{13}=\left\{j, V_{1 j} \geq V_{3 j}\right\}$, Untuk $\mathrm{j}=1,2,3, \ldots, 5$ $=\{2,3,4,5\}$

$C_{21}=\left\{j, V_{2 j} \geq V_{1 j}\right\}$, Untuk $\mathrm{j}=1,2,3, \ldots, 5$ $=\{5\}$

$C_{23}=\left\{j, V_{2 j} \geq V_{3 j}\right\}$, Untuk $\mathrm{j}=1,2,3, \ldots, 5$ $=\{3,4,5\}$

$C_{31}=\left\{j, V_{3 j} \geq V_{1 j}\right\}$, Untuk $\mathrm{j}=1,2,3, \ldots, 5$ $=\{1,2\}$

$C_{32}=\left\{j, V_{3 j} \geq V_{2 j}\right\}$, Untuk $\mathrm{j}=1,2,3, \ldots, 5$ $=\{1,2,4\}$

b. Discordance

Sebuah kriteria dalam suatu alternatif termasuk discordance jika :

$D_{k l}=\left\{j, V_{k l} \geq V_{l j}\right\}$, Untuk $\mathrm{j}=1,2,3, \ldots, \mathrm{n}$

$D_{12}=\left\{j, V_{1 j} \geq V_{2 j}\right\}$, Untuk $\mathrm{j}=1,2, \ldots, 5$

$=\{\}$

$D_{13}=\left\{j, V_{1 j} \geq V_{3 j}\right\}$, Untuk $\mathrm{j}=1,2, \ldots, 5$

$=\{1\}$

$D_{21}=\left\{j, V_{2 j} \geq V_{1 j}\right\}$, Untuk $\mathrm{j}=1,2, \ldots, 5$

$=\{1,2,3,4\}$ 


$$
\begin{aligned}
D_{23} & =\left\{j, V_{2 j} \geq V_{3 j}\right\}, \text { Untuk } \mathrm{j}=1,2, \ldots, 5 \\
& =\{1,2\} \\
D_{31} & =\left\{j, V_{3 j} \geq V_{1 j}\right\}, \text { Untuk } \mathrm{j}=1,2, \ldots, 5 \\
& =\{3,4,5\} \\
D_{23} & =\left\{j, V_{3 j} \geq V_{2 j}\right\}, \text { Untuk } \mathrm{j}=1,2, \ldots, 5 \\
& =\{3,5\}
\end{aligned}
$$

4. Menghitung matriks concordance dan discordance

$$
\begin{aligned}
C_{k l} & =\sum_{j \in C_{k l}} w_{j} \\
C_{12} & =w_{1+}+w_{2+} w_{3+} w_{4}+w_{5} \\
& =5+3+4+4+2=18 \\
C_{13} & =w_{2+} w_{3+} w_{4}+w_{5} \\
& =3+4+4+2=13 \\
C_{21} & =w_{5} \\
& =2 \\
C_{23} & =w_{3+} w_{4}+w_{5} \\
& =4+4+2=10 \\
C_{31} & =w_{1+} w_{2} \\
& =5+3=8 \\
C_{32} & =w_{1+} w_{2+} w_{4} \\
& =5+3+4=12
\end{aligned}
$$

Jadi Matriks Concordance adalah :

$$
\text { Г } \begin{array}{r}
-1813 \\
2-10
\end{array}
$$

L $812-$

B . Menghitung Matriks discordance

$$
\begin{aligned}
& D_{k l}=\frac{\max \left\{\left[V_{k j}-V_{1 j}\right]\right\}}{\max \left\{\left[V_{k j}-V_{1 j}\right]\right\} \vee j} j \in D_{k l} \\
& =\frac{\max \{0\}}{\max \{[2,8285-2,1215] ;] 1,8741-1,4055] ; 2,9816-2,3852] ;] 2,9104-1,9404] ;] 1,2792-1,2792} \\
& \quad=\frac{\max \{0\}}{\max \{0,7070 ; 0,4686 ; 0,5964 ; 0,9700 ; 0\}} \\
& \quad=\frac{0}{0,9700} \\
& \quad=0 \\
& =\frac{\max \left\{\left[V_{1 j}-V_{3 j}\right]\right\}}{\max \left\{\left[V_{1}-V_{3 j}\right]\right\} \vee j} j \in D_{13} \\
& =\frac{\max \{[2,8285-3,5355] ;[1,8741-1,8741] ;[2,9816-1,1924] ;[2,1904-1,9404] ;[1,2792-0,8528]\}}{\max \{0,7070 ; 0 ; 1,7892 ; 0,9701 ; 0,4264\}} \\
& =\frac{0,7070}{1,7893} \quad \max \{[2,8285-3,5355]\} \\
& =0,3951 \\
& D_{21}=\frac{\max \left\{\left[V_{2 j}-V_{1 j}\right]\right\}}{\max \left\{\left[V_{2 j}-V_{1 j}\right]\right\} \vee j} j \in D_{21} \\
& =\frac{\max \{[2,1215-2,8285] ;[1,4055-1,8741] ;[2,3852-2,9816] ;[2,9104-1,9404]\}}{\max \{[2,1215-2,8285] ;[1,4055-1,8741] ;[2,3852-2,9816] ;[2,9104-1,9404] ;[1,2792-1,2792]\}}
\end{aligned}
$$$$
=0,3951
$$ 


$$
\begin{aligned}
& \frac{\max \{0,7070 ; 0,4648 ; 0,5964 ; 0,9700\}}{\max \{0,7070 ; 0 ; 0,4648 ; 0,5964 ; 0,9700 ; 0\}} \\
& =\frac{0,9700}{0,9700} \\
& =1 \\
& D_{23}=\frac{\max \left\{\left[V_{2 j}-V_{3 j}\right]\right\}}{\max \left\{\left[V_{2 j}-V_{3 j}\right]\right\} \vee j} j \in D_{23} \\
& =\frac{\max \{[2,1215-3,5355] ;[1,4055-1,8741]\}}{\max \{[2,1215-3,5355] ;[1,4055-1,8741]\}} \\
& \frac{\max \{[0,7070 ; 0,4686 ; 0,5964 ; 0,9700]\}}{\max \{0,7070 ; 0,4686 ; 0,5964 ; 0,9700 ; 0]\}} \\
& =1 \\
& D_{31}=\frac{\max \left\{\left[V_{3 j}-V_{1 j}\right]\right\}}{\max \left\{\left[V_{3 j}-V_{1 j}\right]\right\} \vee j} j \in D_{31} \\
& \max \{[1,1924-2,9816] ;[1,9404-2,9104] ;[0,8528-1,2792]\}
\end{aligned}
$$

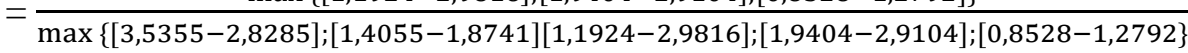

$$
\begin{aligned}
& =\frac{\max \{[1,7892 ; 0,9700 ; 0,4264]\}}{\max \{[0,707 ; 0 ; 1,7892 ; 0,9700 ; 0,4264]\}} \\
& =\frac{1,7892}{1,7892} \\
& =1 \\
& D_{32}=\frac{\max \left\{\left[V_{3 j}-V_{2 j}\right]\right\}}{\max \left\{\left[V_{3 j}-V_{2 j}\right]\right\} \vee j} j \in D_{32} \\
& =\frac{\max \{[1,1924-2,3852] ;[0,5828-1,2792]\}}{\max \{[3,5355-2,1215] ; 11,8741-1,4055][1,1924-2,3852] ;[1,9404-2,} \\
& =\overline{\max \{[3,5355-2,1215] ;[1,8741-1,4055][1,1924-2,3852] ;[1,9404-2,9104] ;[0,8528-1,2792\}} \\
& =\frac{\max \{[1,1928 ; 0,4264]\}}{\max \{[1,4141 ; 0,4686 ; 1,1928 ; 0 ; 0,4} \\
& =\overline{\max \{[1,4141 ; 0,4686 ; 1,1928 ; 0 ; 0,4264]\}} \\
& =\frac{1,1928}{1,1928} \\
& =1 \\
& \text { Jadi matrikc discordance adalah : |- } 00,0,3951 \\
& \left|\begin{array}{ccc}
1 & - & 1 \\
1 & 1 & -
\end{array}\right|
\end{aligned}
$$

5. Menetukan matrik dominan concordance dan discordance

a. Menghitung matriks dominan concordance

$$
\begin{aligned}
& \text { Nilai threshold (C) adalah : } \\
& \begin{aligned}
\underline{C} & =\sum_{k=1}^{m} \quad \sum_{l=1}^{m} \quad C_{k l} \\
& =\frac{18+13+2+10+8+12}{3(3-1)} \\
& =\quad \frac{63}{6}=10,5
\end{aligned}
\end{aligned}
$$

Element matriks $\mathrm{F}$ ditemukan sebagai berikut :

$$
\begin{aligned}
F_{k l}= & \left\{1, j i k a C_{k l} \geq \stackrel{C}{-}\right\} \\
& \left\{0, \text { jika } C_{k l}<\frac{C}{}\right\}
\end{aligned}
$$

Sehingga matriks dominan concordance adalah :

$$
\boldsymbol{F}=\begin{array}{lll}
- & 1 & 1 \\
0 & 1 & 0
\end{array}
$$

b. Menghitung matriks dominan discordance

Nilai threshold $\odot$ adalah : 


$$
\begin{aligned}
\underline{d} & =\sum_{k=1}^{m} \begin{array}{c}
\sum_{l=1}^{m} \quad d_{k l} \\
\mathrm{~m}(\mathrm{~m}-1)
\end{array} \\
& =0+0,3951+1+1+1+1 \\
& =\frac{4,9351}{6} \quad \begin{array}{c}
3(3-1) \\
=0,7325
\end{array}
\end{aligned}
$$

Dan elemen matriks G ditentukan sebagai berikut :

$$
\begin{aligned}
G_{k l}= & \left\{1, \text { jika } d_{k l} \geq \stackrel{d}{-}\right\} \\
& \left\{0, \text { jika } d_{k l}<\frac{d}{-}\right\}
\end{aligned}
$$

Sehingga matriks dominan discordance adalah :

$$
\boldsymbol{G}=\begin{array}{ccc}
- & 0 & 0 \\
1 & - & 1 \\
1 & 1 & -
\end{array}
$$

6. Menentukan aggregate dominance matrix

Rumus umum untuk anggota matriks aggregate dominance adalah :

\begin{tabular}{|c|c|c|c|c|}
\hline \multicolumn{5}{|l|}{ SPK Metode Electre } \\
\hline \multicolumn{5}{|l|}{ Home | Electre | Analisa | Login } \\
\hline \multicolumn{5}{|c|}{ Analisa Menggunakan SPK Metode Electre } \\
\hline & \multicolumn{3}{|c|}{ Perhitungan } & \\
\hline & Ranking & Alternatif & Nilai & \\
\hline & 1 & Paket Weding 2 & 1 & \\
\hline & 2 & Paket Weding 1 & o & \\
\hline & 3 & Paket Weding 3 & o & \\
\hline & 4 & Paket Wedding 4 & o & \\
\hline & 5 & wedding 3 & o & \\
\hline \multicolumn{5}{|c|}{ Alternatif Produk Terbaik $=$ Paket Weding 2 dengan Jumlah Nilai 1 Terbanyak $=1$} \\
\hline (C) 2014 ContohProgram.com & & & & Kontak $\mid$ About \\
\hline
\end{tabular}

$$
e_{k l}=f_{k l} \times g_{k l}
$$

$e_{12}=f_{12} \times g_{12}=1 \times 0=0$

$$
\begin{aligned}
& e_{13}=f_{13} \times g_{13}=1 \times 0=0 \\
& e_{21}=f_{21} \times g_{21}=0 \times 1=0 \\
& e_{23}=f_{23} \times g_{23}=0 \times 1=0 \\
& e_{31}=f_{31} \times g_{31}=1 \times 0=0 \\
& e_{32}=f_{32} \times g_{32}=1 \times 1=1
\end{aligned}
$$

Sehingga matriks aggregate dominan adalah :

Hasil akhir

$$
\boldsymbol{E}=\begin{array}{ccc}
- & 0 & 0 \\
0 & - & 0 \\
0 & 1 & -
\end{array}
$$

Alternatif Produk Terbaik $=$ Paket Wedding yang keluar dengan Jumlah Nilai Terbanyak .

Gambar 6 Hasil Akhir

\section{Jurnal Ilmiah SISFOTENIKA}


Dengan pengujian black-box, data yang dimasukkan lalu diproses oleh prodram aplikasi yang dibuat. Pengujian ini dilakukan agar dapat diketahui apakah fungsi dari program aplikasi menghasilkan output yang benar dan sesuai dengan spesfikasi rancangan. Jika pada waktu pengujian program, output yang dihailkan tidak sesuai dengan kebutuhan fungsionalnya, berarti masih terdapat kesalahan pada program aplikasi tersebut, dan selanjutnya akan dilakukan perbaikan (debugging) untuk memperbaiki kesalahan yang terjadi stelah proses pengujian program, proses kerja ini juga dapat disebut dengan trial and Error.

Pada pengujian perangkat lunak Spk ini, penulis menggunakan blackbox

Metode pengujian ini tidak memperhatikan struktur internal atau sifat dari sebuah program atau modul. blackbox menggunakan strategi dengan melakukan pengujian data secara menyeluruh.

Dengan pengujian blackbox, data yang dimasukkan lalu diproses oleh program aplikasi menghasilkan output yang benar dan sesuai dengan spesifikasi rancangan. Jika pada waktu pengujian program, output yang menghasilkan tidak sesuai dengan kebutuhan fungsionalnya, berarti masih terdapat kesalahan pada program aplikasi tersebut, dan selanjutnya akan dilakukan perbaikan (debugging) untuk memperbaiki kesalahan yang terjadi setelah proses pengujian program.

\section{KESIMPULAN}

Sistem Pendukung Keputusan ini dibangun dengan tujuan untuk memberikan rekomendasi tema skripsi yang akan diambil oleh peneliti.

Sistem pendukung keputusan ini dibangun dengan kriteria pemilihan paket wedding yang berbasis web,

Sistem Pendukung Keputusan ini menggunakan metode ELECTRE dimana hasil akhir dari proses pendukung penentuan tema skripsi ini adalah menghasilkan paket wedding sesuai perhitungan metode ELECTRE. Alternetif dengan bobot tertinggilah yang menjadi hasil akhir dalam pemilihan paket wedding ini.

\section{SARAN}

Dalam pengembangan system selanjutnya disarankan untuk menggunakan kriteria penentuan berbasis yang berbeda dengan yang dipakai sekarang. Misalkan berbasis mobile untuk mengambil keputusan untuk kriteria penentuan. Dengan system yang telah dibangun ini mempunya sifat dinamis, dan diharapkan pada saat melakukan perubahan kriteria penentuan system ini akan lebih mudah dibandingkan dengan Sistem Pendukung keputusan yang bersifat statis. Berdasarkan hasil pembahasan dan kesimpulan, maka dapat diambil beberapa saran yaitu pengembangan lebih lanjut diperlukan agar bisa disesuaikan dengan kebutuhan Paket Wedding Pontianak serta pengoperasian secara maksimal dari aplikasi Sistem Pendukung Keputusan perlu adanya perangkat keras dan perangkat lunak maksimal.

\section{UCAPAN TERIMA KASIH}

Penulis mengucapkan terima kasih kepada dosen pembimbing, orang tua serta sabahat yang telah memberi dukungan finansial terhadap penelitian ini.

\section{DAFTAR PUSTAKA}

[1] Marlinda, L. (2016). Sistem pendukung keputusan pemilihan tempat wisata yogyakarta menggunakan metode ELimination Et Choix Traduisant La RealitA (ELECTRE). Prosiding Semnastek. 
[2] Kosasi, S., \& David, D. (2013). Sistem Penunjang Keputusan Pembelian Mobil Menggunakan Adaptive Neuro Fuzzy Inference System. Prosiding SeNAIK, 74-80.

[3] Setiawan, F., Indriani, F., \& Aziz, M. (2016). Implementasi Metode Electre Pada Sistem Pendukung Keputusan SNMPTN Jalur Undangan. Klik-Kumpulan Jurnal Ilmu Komputer, 2(2), 197-120.

[4] Setiwati, Hartati, Maulana melakukan penelitian tentang "Sistem Pendukung Keputusan Pembelian Barang Menggunakan Metode ELECTRE". Dalam melakukan pembelian barang, ada beberapa kriteria yang digunakan oleh Denco Variasi.

[5] Sundari, S., Wanto, A., \& Gunawan, I. (2017). Sistem Pendukung Keputusan Dengan Menggunakan Metode Electre Dalam Merekomendasikan Dosen Berprestasi Bidang Ilmu Komputer (Study Kasus di AMIK \& STIKOM Tunas Bangsa). 